\title{
GABAergic/Glutamatergic-Glial/Neuronal Interaction Contributes to Rapid Adaptation in Pacinian Corpuscles
}

\author{
Lorraine Pawson, ${ }^{1}$ Laura T. Prestia, ${ }^{1,2}$ Greer K. Mahoney, ${ }^{1}$ Burak Güçlü, ${ }^{1,3}$ Philip J. Cox ${ }^{1,2}$ and Adam K. Pack ${ }^{1,2}$ \\ ${ }^{1}$ Institute for Sensory Research, Department of Biomedical and Chemical Engineering, Syracuse University, Syracuse, New York 13244, ${ }^{2}$ Department of \\ Biology, Utica College, Utica, New York 13502, and '3Biomedical Engineering Institute, Bogaziçi University, 34342 Bebek, Istanbul, Turkey
}

Pacinian corpuscles (PCs) are tactile receptors composed of a nerve ending (neurite) that is encapsulated by layers of lamellar cells. PCs are classified as primary mechanoreceptors because there is no synapse between the transductive membrane and the site of actionpotential generation. These touch receptors respond in a rapidly adapting manner to sustained pressure (indentation or displacement), which until now was believed to be attributable solely to the mechanical properties of the capsule. However, evidence of positive immunoreactivity for GABA receptors on the neurite, as well as evidence for gene expression of synaptobrevin in the lamellar cells led to the hypothesis that GABAergic inhibition originating from the lamellar cells is involved in the rapid adaptation process of PCs. Electrophysiological data from isolated PCs demonstrates that, in the presence of either gabazine or picrotoxin (GABA receptor antagonists), many action potentials appear during the static portion of a sustained indentation stimulus (similar to slowly adapting receptors) and that these "static" spikes completely disappear in the presence of GABA. It was consequently hypothesized that glutamate, released by either the neurite itself or the lamellar cells, caused these action potentials. Indeed, the glutamate receptor blocker kynurenate either decreased or totally eliminated the static spikes. Together, these results suggest that GABA, emanating from the modified Schwann cells of the capsule, inhibits glutamatergic excitation during the static portion of sustained pressure, thus forming a "mechanochemical," rather than purely mechanical, rapid adaptation response. This glial-neuronal interaction is a completely novel finding for the PC.

\section{Introduction}

An enormous amount of information concerning the sense of touch has been gleaned from the Pacinian corpuscle (PC), an onion-shaped tactile receptor in the skin. It was discovered in the 18 th century and later described by many authors, one of whom was Filippo Pacini (1838). Since the 1950s, investigators have known that the PC enables the detection of tiny vibrations in our environment (Gray and Malcolm, 1950; Sato, 1961) and is most sensitive to $\sim 250 \mathrm{~Hz}$ when stimulated with sinusoidal stimuli (Bolanowski and Verrillo, 1982; Bell et al., 1994). At the center of this tactile receptor lies a nerve ending that is encapsulated by inner-core hemi-lamellae derived from Schwann cells (Zelená, 1978; Pawson et al., 2000), which in turn are surrounded by outer-core lamellae developed from fibroblasts (Pease and Quilliam, 1957; Spencer and Schaumburg, 1973; Zelená, 1994). Davis (1961) classified the PC as a primary mechanoreceptor, meaning that there is no synapse between the site of receptor-potential origin (transductive membrane) and the site of action-potential generation. Electrophysiologists have categorized this tactile receptor as "rapidly adapting" (RA) because of its action-potential

Received Dec. 16, 2008; accepted Dec. 28, 2008.

This work was supported by National Institutes of Health/National Institute of Neurological Disorders and Stroke Grant NS036816. We dedicate this work to Dr. S. J. Bolanowski and Dr. R. T.Verrillo. We thank Drs. Laurel Carney, R. L. Smith, Bart Farell, and Peter Pawson for helpful critiques of this manuscript, as well as Dr. Michael Anzalone and Eric Lorraine for technical assistance.

Correspondence should be addressed to Adam K. Pack, Institute for Sensory Research, 621 Skytop Road, Syracuse University, Syracuse, NY 13244-5290. E-mail: apack@utica.edu.

D01:10.1523/JNEUROSCI.5974-08.2009

Copyright $\odot 2009$ Society for Neuroscience $\quad$ 0270-6474/09/292695-11\$15.00/0 response pattern when stimulated by a "ramp-and-hold" stimulus (Gray and Matthews, 1951), in which spikes occur during the dynamic phase (on and off portions of the ramps) of the stimulus, whereas there are few or no spikes seen in the static (hold) portion.

In the past, investigators proposed that the RA response of the PC could be explained entirely by the mechanical properties of the capsule (Hubbard, 1958; Loewenstein and Mendelson, 1965; Loewenstein and Skalak, 1966). Results from our laboratory show positive immunoreactivity in the inner-core hemi-lamellae for glutamate receptors, vesicular-glutamate transporters, and the synaptic proteins synaptobrevin [vesicle-associated membrane protein 2 (VAMP2)] and SNAP-23 (Pawson et al., 2007). Also, recent findings of many investigators have shown release of neurotransmitters (glutamate, GABA) from glial cells when they are stimulated by glutamate, ATP, or even mechanical motion (Cornell-Bell et al., 1990; Nedergaard, 1994; Parpura et al., 1994; Innocenti et al., 2000; Araque et al., 2000, 2001; Kozlov et al., 2006). These results, plus those implicating glutamate involvement in the "slowly adapting" (SA) response of Merkel cell-neurite complexes (MCN) (Fagan and Cahusac, 2001; Cahusac and Senok, 2006), as well as the proposed "autogenic" stimulation of the neurite by glutamate seen in the muscle spindle by Bewick et al. (2005), led to the following hypothesis: action potentials in response to dynamic (onset or offset) stimuli are attributable to depolarization of the neurite by cations entering mechanogated channels that are opened because of mechanical motion, but action potentials in the static portion of the RA response of the PC are attributable to glutamatergic excitation, which are then inhib- 
ited by GABA released from the modified Schwann cells of the inner core. The results presented in this study suggest that, in the PC, GABA emanating from the capsule inhibits glutamate excitation (stemming from either the neurite itself or the capsule), leading to a glial-neuronal "mechanochemical," rather than solely mechanical, RA response to sustained pressure.

\section{Materials and Methods}

Eleven purpose-bred female cats were obtained from Liberty Research and housed at Syracuse University. The results of this study were obtained from experiments approved by the Institutional Animal Care and Use Committee of Syracuse University.

\section{Electrophysiology}

For a complete description of the surgical procedures used to remove the PCs from cat mesentery, see Bolanowski and Zwislocki (1984). Responses were recorded from PCs $(n=12)$ isolated from cat mesentery. The animals were anesthetized with ketamine purchased from J.A. Webster $(20 \mathrm{mg} / \mathrm{kg})$ before placing an intravenous line. Then doses of sodium pentobarbital $(2.5 \mathrm{mg} / \mathrm{kg})$ were administered intravenously until a surgical plane of anesthesia (areflexia) was induced, as evidenced by total lack of the palpebral reflex. A tracheotomy was performed, and then the animal was shaved to allow a midline laparotomy for exposure of the peritoneal cavity. Pieces of mesentery containing PCs were removed as needed. The animal was placed on a heating pad to maintain rectal temperature at $37-39^{\circ} \mathrm{C}$. Throughout the entire surgical procedure the plane of anesthesia was sustained at the level of areflexia by supplemental intravenous doses of sodium pentobarbital $(2.5 \mathrm{mg} / \mathrm{kg})$, at which point both rectal temperature and heart rate were monitored and recorded. At the termination of the experiment, the animal was killed by an overdose of intravenous sodium pentobarbital (100 mg/kg).

The preparation (mesenteric tissue containing PCs) was placed on a pedestal in a dissecting/recording chamber located in a sound- and vibration-isolation room (Acoustic Systems). The preparation was perfused at $\sim 2.25 \mathrm{ml} / \mathrm{min}$ through a gravity-fed system with a KrebsHenseleit (Krebs') solution through which 95\% $\mathrm{O}_{2}$ and $5 \% \mathrm{CO}_{2}$ gas was continuously bubbled. The Krebs-Henseleit composition was as follows (in $\mathrm{mM}$ ): $115 \mathrm{NaCl}, 4.6 \mathrm{KCl}, 1.9 \mathrm{CaCl}_{2}, 1.1$ $\mathrm{MgSO}_{4}, 0.8 \mathrm{KH}_{2} \mathrm{PO}_{4}, 24 \mathrm{NaHCO}_{3}$, and 10 D-glucose. The solution was adjusted to a $\mathrm{pH}$ of 7.2-7.4. Once the mesentery resection was secured in the chamber, a nerve fiber innervating a PC was dissected free, cut proximally, and pulled into a suction electrode containing Krebs' solution.

The dosage of GABA in all experiments was $0.5 \mathrm{M}$, but the amount of gabazine varied. The gabazine concentration in Figure 4 was $0.3 \mathrm{~mm}(i)$ and $0.1 \mathrm{~mm}(\mathrm{ii})$. The concentration of picrotoxin was $4 \mathrm{~mm}$ and that of kynurenate was either $20 \mathrm{~mm}$ (see Fig. 5i,ii) or $10 \mathrm{~mm}$ (see Fig. 7iv). All solutions were made up in Krebs' solution, bubbled with $95 \% \mathrm{O}_{2}$ and 5\% $\mathrm{CO}_{2}$ and delivered in the manner as for Krebs' solution mentioned previously. Although concentrations of experimental solutions were calculated before delivery, the concentration within the experimental chamber reached a maximum over time as the solution was dripped in at $\sim 2.25$ $\mathrm{ml} / \mathrm{min}$. Thus, the final concentrations at the time of data collection were

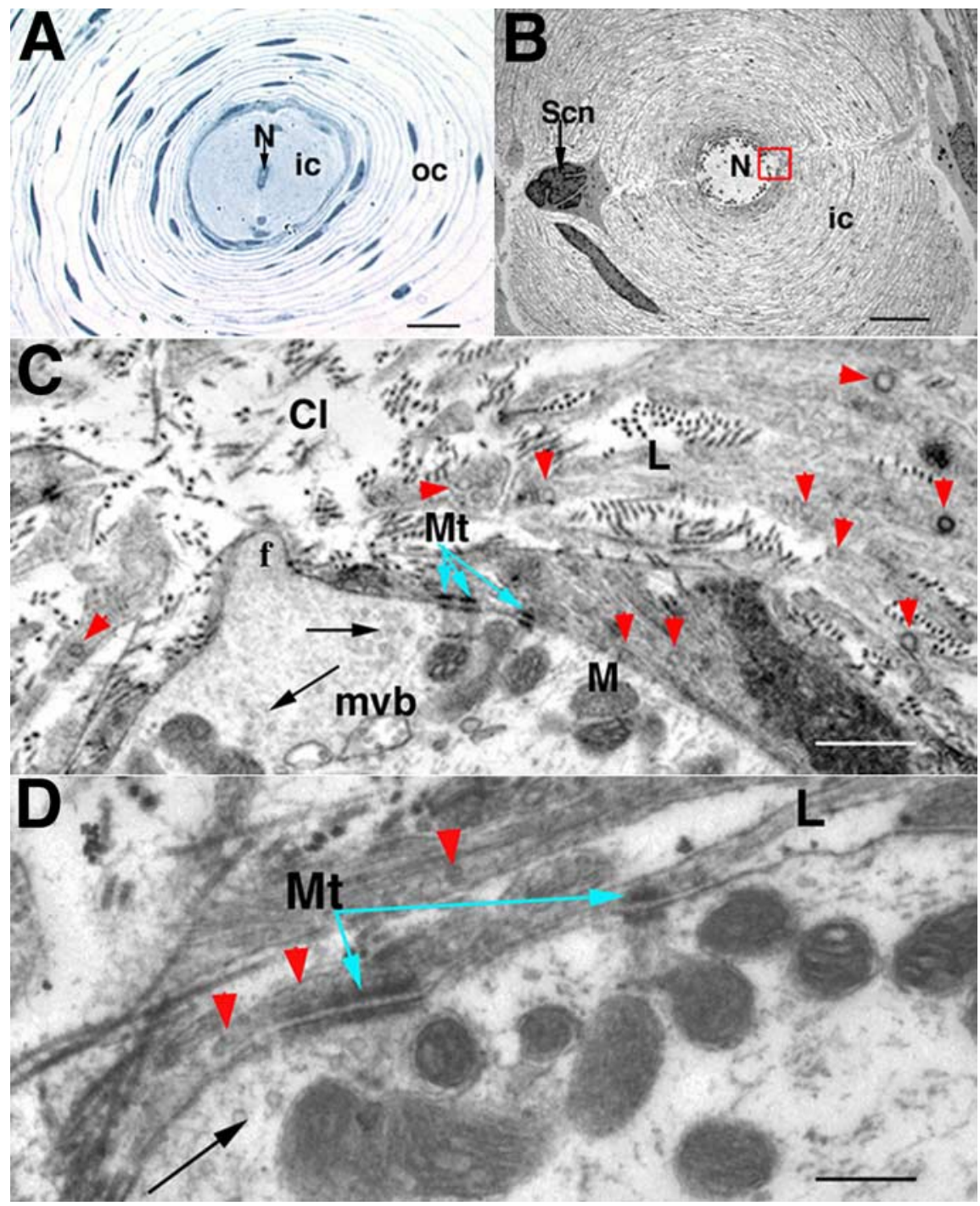

Figure 1. Light and electron microscopic images of cross-sections cut through the terminal portion of cat mesenteric Pacinian corpuscles. $A$, Light micrograph image of a $1 \mu \mathrm{m}$ section depicting the inner core (ic) and outer core (oc) lamellar cells as well as the neurite (N). Scale bar, $20 \mu \mathrm{m}$. B, Low-magnification electron micrograph of an $80 \mathrm{~nm}$ cross-section through the terminal C, Magnification of the area in the small rectangle encompassing one tip of the neurite seen in Figure $1 B$, showing a filopodium ( $f$ ) extending into the hemi-lamellar cleft (Cl) formed by the inner-core hemi-lamellae (L). Red arrowheads point to clear-core Within the neurite, a multivesicular body (mvb) and several mitochondria (M) are visible. Scale bar, $640 \mathrm{~nm}$. D, Highmagnification EM depicting the Mts of the lamellar cells and the neurite where they contact each other. Scale bar, $460 \mathrm{~nm}$.

not directly measured and are given as approximations. All pharmacological agents were purchased from Sigma.

The stimulator consisted of a Plexiglas probe mounted onto a calibrated MK2 Fong vibrator (company no longer exists). Calibrations relating stimulus displacements to voltage inputs were made with a KD100 Fotonic sensor (Medical Technology Instruments). These values were used to determine stimulus amplitudes during experimentation; stimulus amplitudes were measured in decibels of displacement $(\mathrm{dB}=20$ $\log$ displacement, relating to $1 \mu \mathrm{m}$ peak). The action potentials recorded in response to the stimuli were amplified $(100 \times)$, bandpass filtered (high frequency, $3 \mathrm{kHz}$; low frequency, $300 \mathrm{~Hz}$ ), and displayed on an oscilloscope. The spikes were passed through a WPI window discriminator, and these discriminated pulses were collected online using a customdesigned LabView (National Instruments) program.

The time course for the ramp-and-hold stimuli (see Fig. 3) for most of the experiments was as follows: $100 \mathrm{~ms}$ off, $100 \mathrm{~ms}$ on-ramp, $500 \mathrm{~ms}$ "hold" [in some experiments the hold duration was $4 \mathrm{~s}$ (see Fig. 6)], 100 


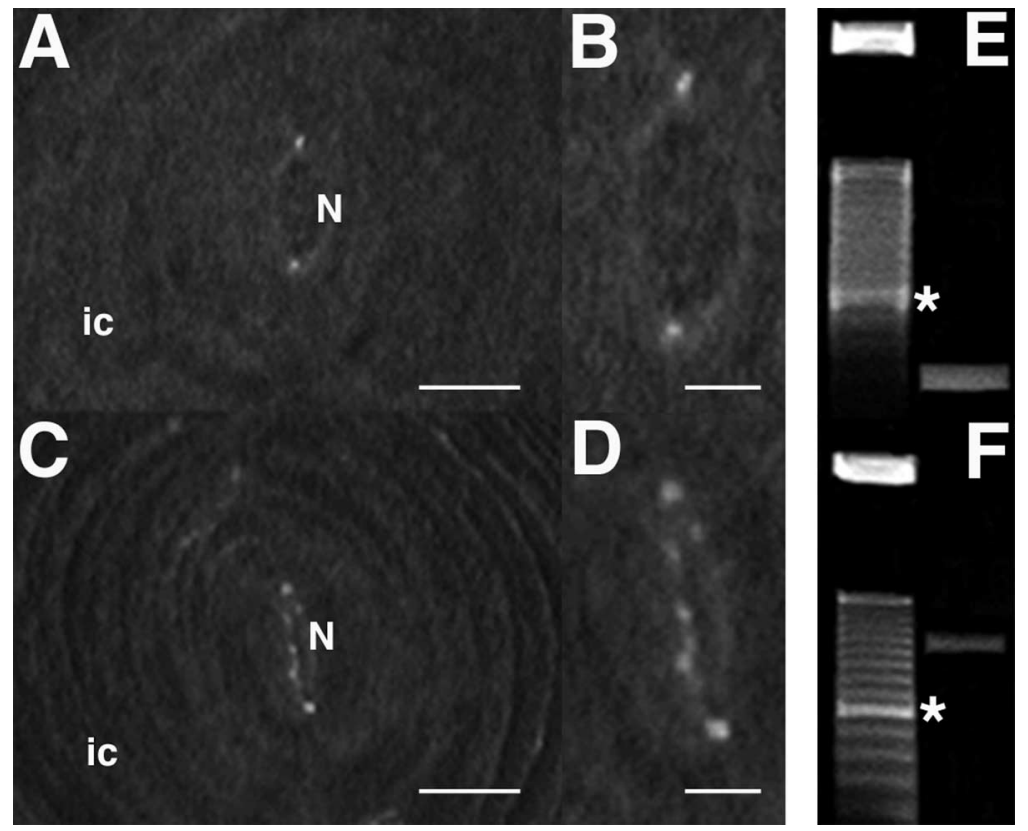

Figure 2. Results of immunocytochemical and RT-PCR experiments depicting synaptic proteins. $A$, Fluorescence micrograph from the same region as Figure $1 A$ depicts labeling for VAMP2. $\boldsymbol{B}$, A higher-magnification image of the neurite of Figure $2 A$. $\boldsymbol{C}$, Fluorescence micrograph image as in Figure $2 A$ labeled with anti-GABA receptor. The labeling is very similar to that seen in Figure 2A.D, A higher-magnification image of the neurite of Figure 2 C. Scale bars: $\boldsymbol{A}, \boldsymbol{C}, 6.5 \mu \mathrm{m} ; \boldsymbol{B}, \boldsymbol{D}, 2.5 \mu \mathrm{m}$. $\boldsymbol{E}$, A Polaroid image of a $1 \%$ agarose electrophoresis gel depicting $P C R$ results from mesenteric $P C$ CDNA mixed with primers for feline $\beta$-actin as well as a 50 bp ladder. A prominent band at $\sim 579$ bp was expected using these $\beta$-actin primers (for control positive purposes). $\boldsymbol{F}, \mathrm{A} 2 \% \mathrm{gel}$ showing results of a $P C R$ product using the CDNA from mesenteric $P C s$ mixed with primers designed for VAMP 2 as well as a 50 bp ladder. The $\sim 192$ bp band was expected using these VAMP2 primers. * denotes the 350 bp band on the ladders. ic, Inner core; N, neurite.

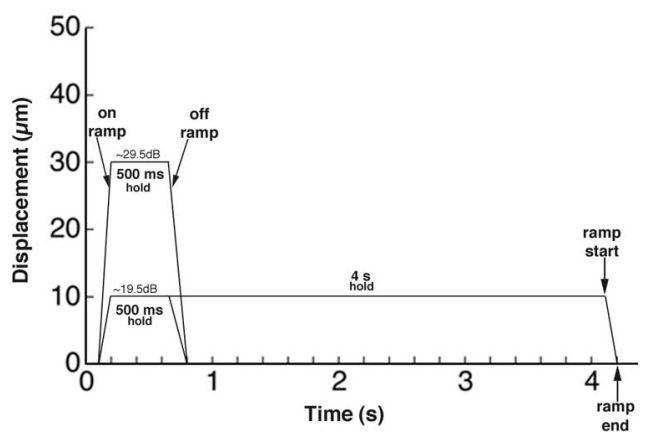

Figure 3. Example of a ramp-and-hold stimulus. In this example, the $200 \mu \mathrm{m}$ probe is indented into the $P C$ in the following manner: the stimulus is off for $100 \mathrm{~ms}$, followed by an on ramp of $100 \mathrm{~ms}$ (i.e., it takes $100 \mathrm{~ms}$ for the probe to reach its final indentation depth), the probe is held at the depth of either $30 \mu \mathrm{m}$ ( $\sim 29.5 \mathrm{~dB}$ relating to $1 \mu \mathrm{m}$ peak) or $9.4 \mu \mathrm{m}(\sim 19.5 \mathrm{~dB}$ relating to $1 \mu \mathrm{m}$ peak) of displacement for $500 \mathrm{~ms}$, and finally the probe is withdrawn back to the baseline starting position over a $100 \mathrm{~ms}$ period (or off ramp). The probe was held for $4 \mathrm{~s}$ in some experiments.

ms off-ramp. However, in one experiment (see Fig. 7iv), the time course was as follows: $10 \mathrm{~ms}$ off, $100 \mathrm{~ms}$ on-ramp, $500 \mathrm{~ms}$ hold, $100 \mathrm{~ms}$ off-ramp. Peristimulus time (PST) histograms with bin widths of $20 \mathrm{~ms}$ were computer generated using the action-potential responses obtained over 10 stimulus presentations of the ramp-and-hold stimuli (see Figs. 4-7).

To examine the frequency characteristics, bursts of sinusoidal displacements at frequencies of $10-500 \mathrm{~Hz}$ were applied to each PC. The stimulus amplitude was adjusted, in increments of $1 \mathrm{~dB}$, to produce neural impulses of $\sim 1$ impulse/s. The data collected for each frequency and amplitude were averaged over 10 stimulus presentations with firing rates determined during the steady state (see Fig. 11). Firing rates in the presence and absence of pharmacological agents were compared using the Wilcoxon's matched-pair signed-rank test. Static and dynamic responses (see Fig. 8) were tested separately.
Light and electron microscopy

Cat mesenteric PCs were placed in a solution of $2 \%$ paraformaldehyde and $2 \%$ glutaraldehyde in $0.1 \mathrm{~m}$ Sorensen's phosphate buffer at a $\mathrm{pH}$ of 7.2-7.4 $\left(\mathrm{PO}_{4}\right)$. PCs were postfixed in a $2 \%$ osmium tetroxide solution in $\mathrm{PO}_{4}$ for $2 \mathrm{~h}$. The tissue was then washed in $\mathrm{PO}_{4}$, dehydrated in ethanol, placed in two changes of pure propylene oxide, infiltrated overnight in a 1:1 solution of propylene oxide and Araldite, and finally embedded in Araldite for $18-24 \mathrm{~h}$ at $60^{\circ} \mathrm{C}$. Light micrographs from $1 \mu \mathrm{m}$ Araldite sections were cut on a Sorvall MT2B ultramicrotome, stained with methylene blue and azure blue II, and photographed with a CCD camera (Optronics) attached to a Zeiss Axioskop. Electron micrographs are from $80 \mathrm{~nm}$ sections that were mounted on copper grids and stained with $1 \%$ uranyl acetate in $25 \%$ ethanol, followed by $0.3 \%$ lead citrate before viewing at $80 \mathrm{kV}$ on a Jeol 100 CXII electron microscope.

\section{Immunocytochemistry}

A complete description of the immunocytochemical procedures used here have been described by Pawson et al. $(2000,2007)$ and Pawson and Bolanowski (2002). Cat mesenteric PCs were fixed in $2 \%$ paraformaldehyde/ $1 \%$ glutaraldehyde in $\mathrm{PO}_{4}$. The tissue was dehydrated and embedded as described above. One micrometer sections of the terminal region of the PCs were etched, fully hydrated, blocked using $25 \%$ normal goat serum (NGS) in PBS, and subsequently incubated overnight in a humid chamber with $50 \mu \mathrm{l}$ of primary antibody (see below). The tissue was washed in PBS and incubated in 25\% NGS, and a 1:200 dilution of secondary antibody (rhodamineconjugated goat anti-rabbit IgG; Accurate Chemical \& Scientific) was placed on the sections at room temperature in a humid chamber for 30 min. The sections were washed, coverslipped using Gel Mount (Biomeda), and viewed using a Zeiss Axioskop fluorescent microscope, and images were captured with a cooled CCD camera.

Primary antibodies, which were purchased from Sigma, were rabbit

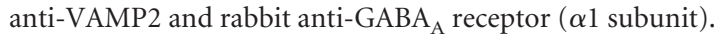

\section{Reverse transcription- $P C R$}

Tissue harvesting. Cerebellum and cerebrum (control tissue) were excised from young female cats after completion of each electrophysiological experiment and frozen at $-80^{\circ} \mathrm{C}$. Pacinian corpuscles were excised from the same animals and used immediately.

DNA extraction. The DNeasy kit from Qiagen was used as per the instructions of the manufacturer for extracting DNA from animal tissue, and all centrifuging was done using a 5417R centrifuge from Eppendorf. To quantify the amount of DNA extracted, a 96-well plate Bio-Tek Instruments Power Wave HT spectrophotometer with Gen 5 software was used with the following equation: [DNA] $=\left(A_{260}\right)(0.05 \mu \mathrm{g} / \mu \mathrm{l})$ dilution.

Isolation of $m R N A$. PCs $(\sim 50$ per isolation $)$ were removed from young female cats, and mRNA was immediately isolated using the MicroFastTrack 2.0 mRNA Isolation kit from Invitrogen. Kit procedures were followed up to the mRNA alcohol precipitation stage when the product was placed at $-80^{\circ} \mathrm{C}$ overnight. Then the mRNA was thawed and centrifuged, the ethanol was removed, elution buffer $(10 \mu \mathrm{l})$ was added to the pellet, and the mRNA was quantified using the spectrophotometer plus this equation: $[\mathrm{RNA}]=\left(A_{260}\right)(0.04 \mu \mathrm{g} / \mu \mathrm{l})$ dilution.

Reverse transcription. cDNA was made from the above mRNA using the Cloned AMV First-Strand cDNA Synthesis kit from Invitrogen and a Thermoline Amplitron II Thermocycler (Barnstead/Thermoline). The amount of cDNA was determined as above. The cDNA was always tested with feline $\beta$-actin primers for control purposes (Rottman et al., 1995).

PCR protocol. The PCR Reagent System from Invitrogen was used for 


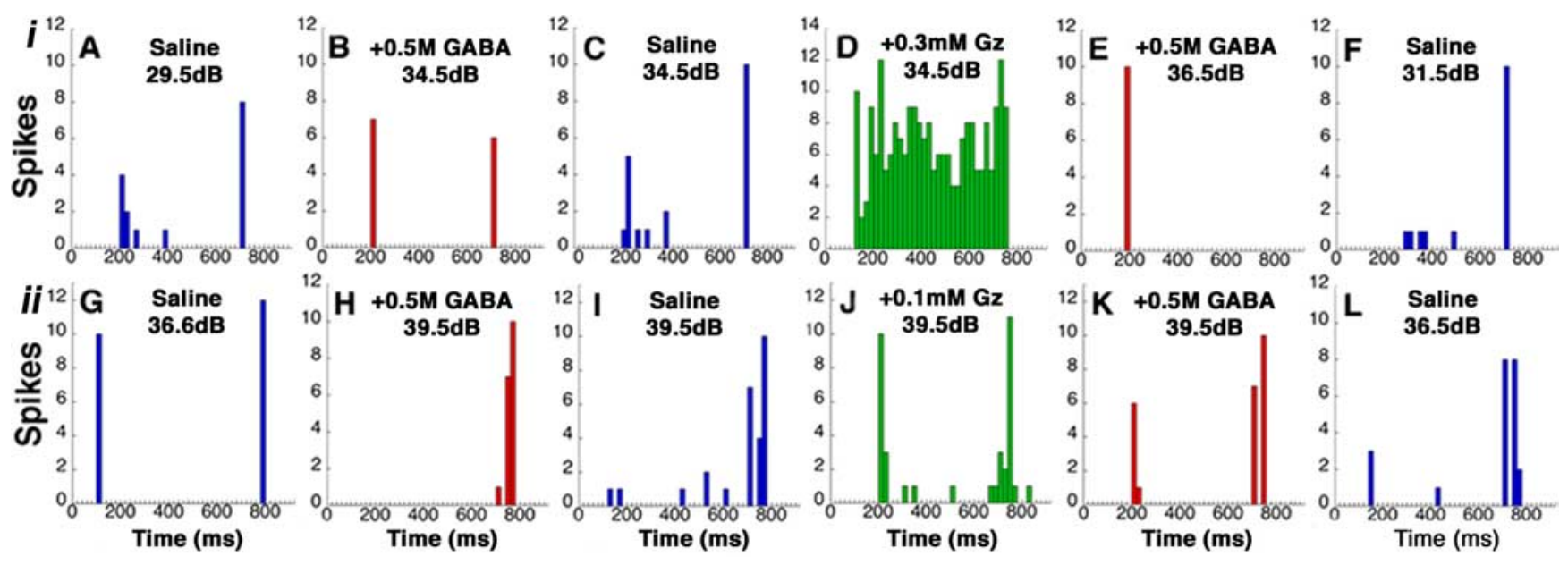

Figure 4. Results of two electrophysiological experiments in which GABA and gabazine (Gz) were applied to the PC. Peristimulus time histograms (bin width of $20 \mathrm{~ms}$ ) depict action potentials recorded from single nerve fibers of isolated cat mesenteric PCs in response to ramp-and-hold stimuli (10 presentations) applied to the body of the tactile mechanoreceptor as the bathing solution was changed. The time course for the ramp-and-hold stimulus was as follows: $100 \mathrm{~ms}$ off, $100 \mathrm{~ms}$ on-ramp, $500 \mathrm{~ms}$ hold, and finally $100 \mathrm{~ms}$ off-ramp. All displacements for the stimuli are described as $\mathrm{dB}$, relating to $1 \mu \mathrm{m}$ peak. $\boldsymbol{A}, \boldsymbol{C}, \boldsymbol{F}, \boldsymbol{G}, \boldsymbol{I}, \boldsymbol{L}$, Krebs-Henseleit saline only (blue); $\boldsymbol{B}, \boldsymbol{E}, \boldsymbol{H}, \boldsymbol{K}, 0.5 \mathrm{~m} G A B A$ (red); $\boldsymbol{D}, 0.3 \mathrm{~mm}$ gabazine (light green); $\boldsymbol{J}, 0.1 \mathrm{~mm}$ gabazine (light green).

all PCR experiments. DNA (gDNA or cDNA) was approximated to the amount (200 ng) used in the control Invitrogen kit. This applied to the concentration of primers as well $(0.5 \mu \mathrm{M})$.

Agarose gel electrophoresis. One or $2 \%$ TAE/ agarose gels $(50 \times$ Tris-acetate/EDTA buffer from Bio-Rad) with $0.5 \mu \mathrm{g} / \mathrm{ml}$ ethidium bromide were used on a Horizon 58 Horizontal Gel Electrophoresis System (model 1060; Invitrogen). Samples were run alongside either 1000 bp or 50 bp TrackIt DNA ladders from Invitrogen and visualized using TrackIt Cyan/Yellow Loading Buffer (Invitrogen). Gels were viewed on a Foto/Prep II UV light box from Fotodyne, and images were captured using a Fotodyne camera and Polaroid film \#667.

Primer design. Primers for VAMP2 were developed based on published rat sequences using the Primer3 Plus Website (http:// www.bioinformatics.nl/cgi-bin/primer3plus/ primer3plus.cgi). Only primer sets that crossed an intron/exon boundary (i.e., gDNA and cDNA products would be different sizes) were ordered from Invitrogen. Primers were reconstituted to a final concentration of $100 \mu \mathrm{M}$ using Tris/EDTA (TE) buffer (Invitrogen 20× TE buffer). The forward primer for VAMP2 from rat was ATGTGGACAAGGTCCTGGAG, and the reverse primer was CACCGATGATGATGATGAGG (primer sequences were $5^{\prime} \rightarrow 3^{\prime}$ ).

Purification of DNA from gel. The RetroPrep Gel Extraction kit from Retrogen was used to purify DNA from bands of interest that were cut out of the agarose gels. The purified DNA was then sent to Retrogen for sequencing. BLAST basic local alignment search tool results (GenBank accession number EU192157) showed 98\% homology with published VAMP2 sequences in mouse (99\%), rat (98\%), monkey (98\%), human $(96 \%)$, and other mammals.

\section{Results}

Immunocytochemistry and reverse transcription-PCR

Cross sections of the terminal portion of cat mesenteric PCs (Fig. $1 \mathrm{~A}$ ) were used for the immunocytochemical experiments (Fig. $2 \mathrm{~A}-$ $D$ ). Fluorescent microscopic images in Figure 2 show positive immunoreactivity using primary antibodies to VAMP2 (Fig. 2A,B) and GABA receptor $1 \mathrm{~A}$ (Fig. $2 C, D$ ), whereas negative controls (i.e., no primary antibody was applied, only secondary antibody) showed
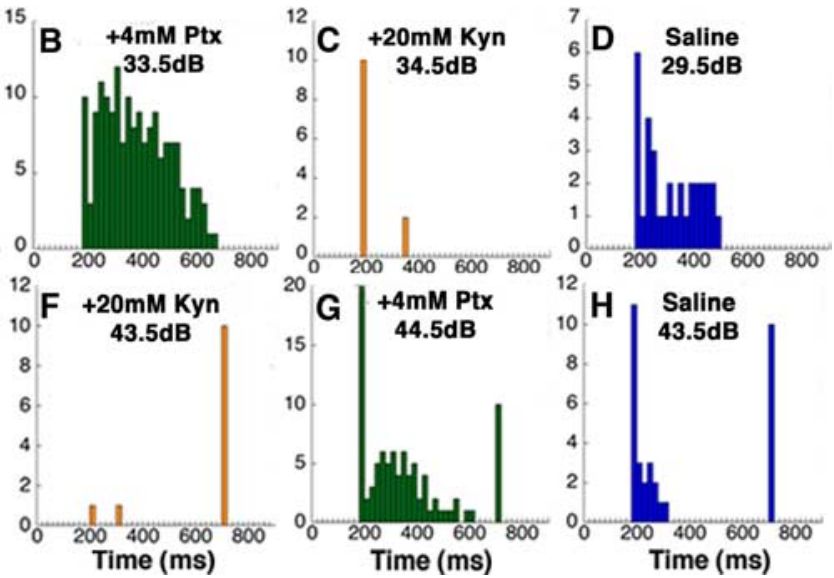

Figure 5. Results from two electrophysiological experiments in which picrotoxin (Ptx), kynurenate (Kyn), and GABA were added to the bathing solution. The ramp-and-hold stimulus and resulting PST histograms are as in Figure 4. A, D, E, H, KrebsHenseleit saline (blue); $\boldsymbol{B}, \boldsymbol{G}, 4$ mm picrotoxin (dark green); $\boldsymbol{C}, \boldsymbol{F}, 20$ mм kynurenate (orange).

no fluorescence. These results show the brightest labeling at the polar tips of the elliptically shaped neurite. At this level of magnification, however, it is difficult to tell whether the labeling is on the neurite or on the tips of the inner-core lamellar cells where they contact the neurite (Fig. $1 B-D$ ). For this reason, it is necessary to consider the reverse transcription (RT)-PCR results using mRNA from lamellar cells of the PC (Fig. 2F), which demonstrate VAMP2 expression within the capsule itself. The presence of VAMP2 (synaptobrevin) on the modified Schwann cells of the lamellae of the PCs also has been demonstrated using immunocytochemical techniques (Pawson et al., 2007). These findings suggest that the lamellar cells may be capable of a "synaptic-like" connection with the neural portion of the PC (neurite), a connection not thought previously to exist. We cannot at this time demonstrate GABA receptors on the neurite with RT-PCR, because those experiments would have to be performed using mRNA that is isolated from PC cell bodies, which are identified in either the trigeminal or dorsal root ganglia.

\section{Electrophysiology}

Electrophysiological experiments $(n=12)$ were designed to test the hypothesis that chemical inhibition contributes to the RA 

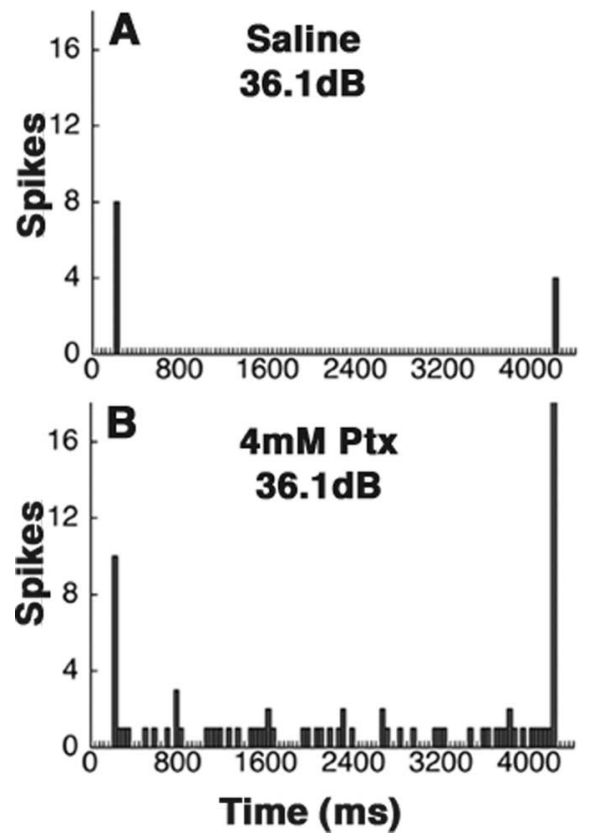

Figure 6. Results from an electrophysiological experiment in which picrotoxin (Ptx) was added to the bathing solution. The ramp-and-hold stimulus and resulting PST histograms are as in Figure 4, except that the hold portion of the stimulus was $4 \mathrm{~s}$ in duration.

response of the PC. PST histograms of action potentials (spikes) over 10 stimulus presentations (bin width of $20 \mathrm{~ms}$ ) depict the firing rate of the receptor when presented with ramp-and-hold stimuli (Fig. 3).

In the first two experiments (Fig. 4i,ii), GABA was applied to the preparation to test for inhibition of action potentials. Gabazine was used in these experiments as the GABA receptor antagonist and was predicted to produce an increase in the discharge rate. The concentration of gabazine varied (Fig. 4, $0.3 \mathrm{~mm}$ in $i$, $0.1 \mathrm{~mm}$ in $i i)$, whereas that of GABA $(0.5 \mathrm{M})$ remained constant. In experiments $i$ and $i$ (Fig. 4), the PCs responded from the beginning as RA receptors (Fig. $4 A, G$ ), with slightly more activity seen in $A$ than in $G$ after the onset. With the addition of GABA, the PC in experiment of Figure $4 i$ became even more rapidly adapting (Fig. $4 B$ ), as determined by the complete absence of spikes in the static portion of the stimulus. In all the cases in which GABA was applied to the bathing solution, no static spikes occurred (Fig. $4 B, E, H, K$ ). With the addition of gabazine, static spikes appear (Fig. $4 D, J$ ), with the greatest number of spikes occurring when the highest concentration of gabazine $(0.3 \mathrm{~mm})$ was applied to the bathing solution (Fig. $4 D)$. The results seen in Figure 4, $C, F, L$, and $I$, in which the bathing solution was returned to saline alone indicate that the effects of GABA (and gabazine) were reversible.

Figure 4 shows that static, but not dynamic, action potentials (although the dynamic were sometimes lowered) disappeared in the presence of GABA and appeared in abundance in the presence of gabazine in a dose-dependant manner. On the basis of these results, it was hypothesized that the static spikes, which appeared when GABA was blocked, were caused by glutamatergic excitation. To test this theory, kynurenate, the glutamate receptor antagonist, was applied to our preparation (as in the study by Fagan and Cahusac, 2001), and it was predicted that the static spikes would decrease.

The PSTs of Figure 5 are the results of experiments in which picrotoxin (GABA receptor antagonist) and kynurenate (a gluta- mate receptor antagonist) were used. In Figure 5, $i$ and $i i$, the PCs did not have an RA response from the beginning of the experiments. However, with the application of kynurenate (20 mM), a more typical RA response was produced (Fig. $5 C, F$ ). This would be expected if glutamate were responsible for the static spikes. In all cases, when $4 \mathrm{~mm}$ picrotoxin was applied to the bathing solution, many static spikes were observed (Fig. $5 B, G$ ). In all cases, the effects of picrotoxin and kynurenate were reversible as evidenced when the PCs subsequently were bathed in saline only (Fig. $5 D, H$ ).

Concentrations of GABA and its antagonists were similar to those used in iontophoretic experiments (Caspary et al., 1994; Backoff et al., 1997, 1999; Jha et al., 2001; Gai and Carney, 2008). The neurite and the modified Schwann cells of the inner core are covered by at least 30 layers of outer lamellae that are joined by tight junctions, as well as an outer five layers of external capsule, making this preparation less readily accessible to drugs than cellculture studies or other tactile receptor preparations, for example, those of Panek et al. (2002) or Fagan and Cahusac (2001). The experimental pharmacological agents were left in the bathing solution until we saw an effect $(\sim 30 \mathrm{~min})$ before returning to pure Krebs' solution. The data for the PSTs of Figure 6 were collected the same as in Figure 5, except that the hold portion of the stimulus was $4 \mathrm{~s}$ in duration. Figure $6 \mathrm{~A}$ was collected before the application of any pharmacological agent, whereas in Figure $6 B, 4 \mathrm{~mm}$ picrotoxin was added to the bathing solution. During the $4 \mathrm{~s}$ duration of Figure $6 B$, spikes were maintained throughout, and this is similar to the stimulus parameters used in experiments done with the slowly adapting MCN mechanoreceptors (Fagan and Cahusac, 2001).

In Figure 7, we show the "pre", "during," and "recovery" stages of each pharmacological agent that was used in this study. To make comparisons, the intensity of the ramp-and-hold stimulus was kept the same in each case. The presence of spikes in Figure 7, $B$ (0.2 mm gabazine) and $E$ (4 mm picrotoxin), during the application of GABA antagonists is dramatically different from $H(0.5 \mathrm{M}$ GABA) in which the inhibitor is applied to the PC. With the application of $10 \mathrm{~mm}$ kynurenate (Fig. $7 \mathrm{~K}$ ), a glutamate antagonist, spikes are no longer seen in the hold or in mid-ramp portions of the stimuli. The PC in this condition only fires at the on and off portions of the ramps (Fig. $7 K$ ). The time course of the ramp-and-hold stimuli in experiment Figure $7 i v$ differed from all others in this study. In Figure 7iv, the stimulus time was as follows: $10 \mathrm{~ms}$ off, $100 \mathrm{~ms}$ on-ramp, $500 \mathrm{~ms}$ hold, $100 \mathrm{~ms}$ off-ramp. For the experiments shown in Figures 4-7, the average time from addition of pharmacological agent (or pure saline) until data collection was $25.1 \pm 1.3 \mathrm{~min}$.

A total of 12 PCs were used in our experiments. GABA was tested on seven PCs, gabazine was used on six, picrotoxin was tested on six, and kynurenate was used on five. A summary of the electrophysiological-pharmacological results can be seen in the scatter plots of Figure 8 . These plots depict the difference between the control (saline alone) condition (always in blue) and experimental (drug added) condition (green, light-green, red, or orange) for each corpuscle. The points represent the number of spikes observed during the "static" (Fig. $8 E$, \#4) plus the mid-rise (Fig. $8 E, \# 2$ ) and mid-fall (Fig. $8 E$, \#6) portions of the ramps. When $0.3 \mathrm{~mm}$ gabazine (Fig. $8 \mathrm{~A}$, light green) was added to the bathing solution $(n=6)$, the spike count in the $\# 2,4$, and 6 (Fig. $8 E$ ) portions of the stimulus increased. Using a Wilcoxon's matched-pairs signed-rank test, the control condition was significantly lower than the experimental condition $(p=0.0277)$. When $4 \mathrm{~mm}$ picrotoxin (Fig. $8 \mathrm{~B}$, dark green) was the experimen- 
tal pharmacological agent $(n=6)$, the control condition was significantly lower than the experimental condition ( $p=$ 0.0277), using the same statistical test. However, when 0.5 M GABA (Fig. $8 C$, red) was added to the bathing solution $(n=7)$, the experimental condition was significantly lower than the control condition $(p=0.0431)$. The addition of $20 \mathrm{~mm}$ kynurenate (Fig. $8 D$, orange) to the bathing solution $(n=5)$ also significantly ( $p=$ 0.0431 ) reduced the spikes seen in the \#2, 4 , and 6 portions of the stimulus (Fig. $8 E$ ). It appears that these parts of the rampand-hold stimulus (\#2, 4, and 6) are "glutamate mediated," whereas the odd numbered portions (the on and off of both ramps) are the "dynamic" portions of the stimulus and are most probably mediated by the opening of mechanogated channels. The spike count did not significantly differ between the control and experimental conditions during the dynamic (Fig. $8 E$, $\# 1,3,5,7)$ parts of the ramp-and-hold stimulus. There were no spikes seen before (Fig. $8 E$, letter B) or after (Fig. $8 E$, letter A) the presentation of the stimuli, which is consistent with the fact that PCs have no spontaneous activity under the normal conditions (Bolanowski and Zwislocki, 1984).

Because the concentrations for picrotoxin and GABA were higher than those used by other investigators (Panek et al., 2002), we decided to use gabazine at much lower concentrations $(10-400 \mu \mathrm{M})$ and also to look at dose-related responses. PSTs from six different PCs in response to ramp-and-hold stimuli acquired just before and $\sim 0.5 \mathrm{~h}$ after addition of gabazine (at six different concentrations) to the bathing solution of the receptor are shown in Figure 9. In each case, additional spikes occur with the addition of gabazine, with more occurring as the concentration of the GABA antagonist is increased. This increasing dose-response curve can be seen in Figure 9M. Also, with the higher doses of GABA blocker, the increase of spikes in the hold portion of the stimulus becomes greater.

Although some of the PCs showed the classic RA response to indentation in the presence of saline alone (Fig. $4 G$,), some did not (Figs. $4 A, 5 A, E$ ). In one of the corpuscles (Fig. $5 A$ ), many static spikes were seen in response to the ramp-and-hold stimuli. We placed this corpuscle in fixative ( $2 \%$ paraformaldehyde and $2 \%$ glutaraldehyde) at the end of the experiment and subsequently examined $1 \mu \mathrm{m}$ sections (Fig. 10). Although a very typical "terminal" portion of the neurite is seen in Figure $10 \mathrm{~A}$, at the distal 200 to $300 \mu \mathrm{m}$, it divides into three distinct neurites (Fig. $10 \mathrm{~B}$ ), each having their own inner core. Thus, it is possible that, because of the position of the contactor on the PC, each may fire at different intervals, producing dynamic spikes during the hold portion of the stimulus.

In all 12 experiments, the PCs demonstrated classic
U-shaped frequency characteristic curves for sinusoidal stimuli ranging from 10 to $500 \mathrm{~Hz}$ when using a criterion of $\sim 1$ spike/s (Bolanowski and Zwislocki, 1984; Bell et al., 1994). In 11 of the experiments, the PCs responded to the best frequency (bf) range (200 to $300 \mathrm{~Hz}$ ) at between -12 and $-5.5 \mathrm{~dB}$ (relating to $1 \mu \mathrm{m}$ peak). This pattern did not change with the addition of any of the pharmacological agents for these 11 experiments. Frequency characteristics that are representative of these 11 experiments are shown in Figure 11, $A$ and $B$. For Figures $5 i$ and $10 B$, the curve flattened out over time (Fig. $11 C$ ). Note also that this experiment was $\sim 4 \mathrm{~h}$ longer than others. However, this receptor (Figs. $5 i, 10 B$ ) responded to the pharmacological agents in a similar manner to that of the PCs that were more sensitive. Figure $11 D-G$ shows tuning curves taken before application of any pharmacological agent (i.e., the PC is bathed in saline alone; blue) and the tuning curve while the receptor is in the presence of a drug. In the presence of $0.3 \mathrm{~mm}$ gabazine (Fig. $11 \mathrm{D}$ ), $4 \mathrm{~mm}$ picrotoxin (Fig. $11 \mathrm{E}$ ), 

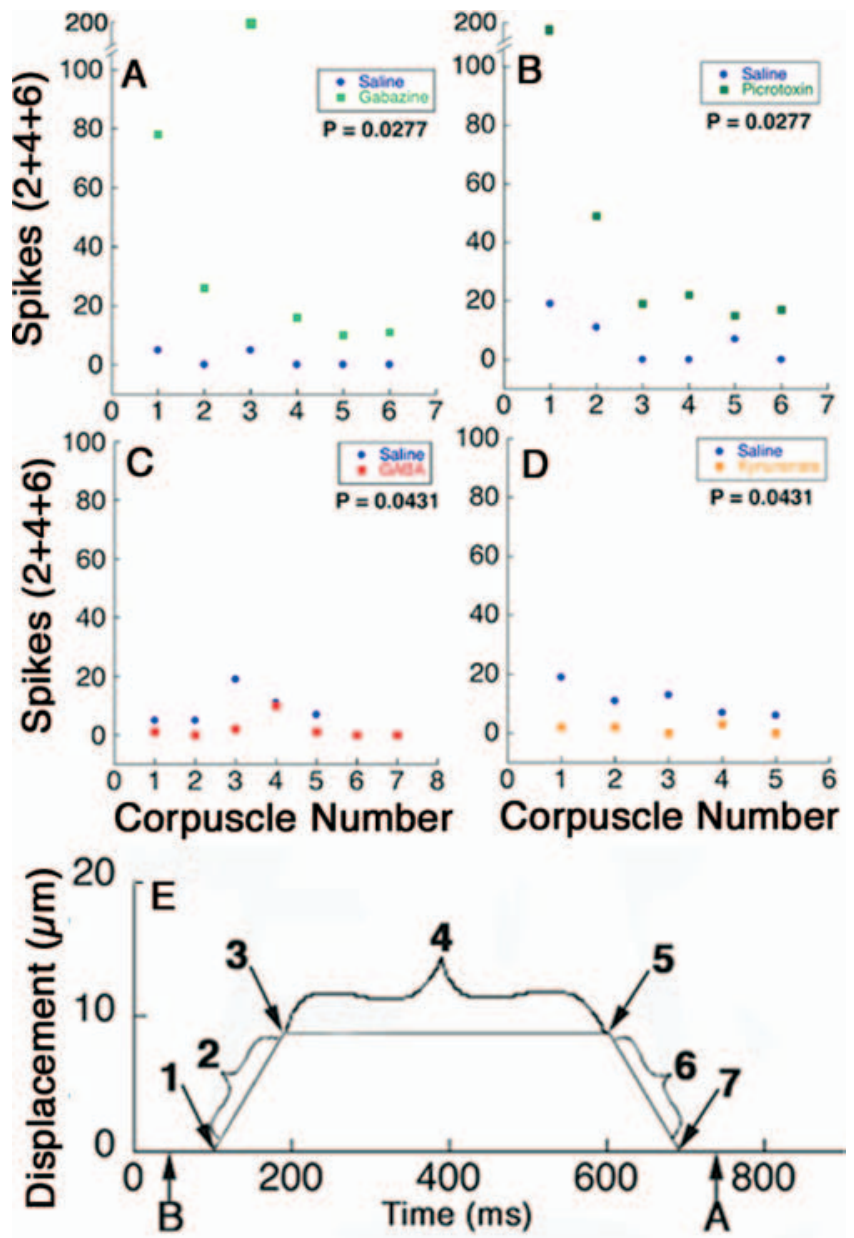

Figure 8. Summary of results for 12 pharmacological experiments. Scatter plots depict for each corpuscle the difference between the control (saline alone) condition (always in blue) and experimental (drug added) condition (either green, light-green, red, or orange). The points represent the number of spikes observed during the static ( $\# 4$ in $E$ ) plus the on or rise ( $\# 2$ in $E$ ) and off or fall ( \#6 in $E$ ) portion of the ramps. It appears that these are the parts of the ramp-andhold stimulus that are glutamate mediated. The even numbered portion of the on and off ramps are the dynamic portions of the stimulus, which are most probably mediated by mechanogated channel opening. $A$, Gabazine at $0.3 \mathrm{~mm}$ (light green) was added to the bathing solution ( $n=$ 6). In all cases, the spike count significantly increased in the $\# 2,4$, and 6 portions of the stimulus $(\boldsymbol{E})$ with the addition of gabazine. The control condition there were fewer spikes than the experimental condition ( $p=0.0277)$. $\boldsymbol{B}$, Picrotoxin at $4 \mathrm{~mm}$ (dark green) was the experimental pharmacological agent $(n=6)$, and, in the control condition, there were significantly fewer spikes than the experimental condition ( $p=0.0277$ ) here as well (for \#2, 4, 6 in E). C, When 0.5 M GABA (red) was added to the bathing solution $(n=7)$, the experimental condition had significantly fewer spikes ( $p=0.0431$ ) than the control for $\# 2,4$, and 6 in E. D, Kynurenate at $20 \mathrm{~mm}$ (orange) added to the bathing solution $(n=5)$ also significantly ( $p=0.0431$ ) reduced the spikes seen in the $\# 2,4$, and 6 portions of the stimulus $(E)$.

and $0.5 \mathrm{M} \mathrm{GABA}$ (Fig. $11 \mathrm{~F}$ ), the sensitivity at the bf (as well as all other frequencies) remains unchanged. Only with the addition of $20 \mathrm{~mm}$ kynurenate (Fig. 11G) does the sensitivity at the bf change slightly (by 3 or $4 \mathrm{~dB}$ ). However, it is safe to say that there does not appear to be any significant difference of sensitivity in the frequency characteristics with the addition of the pharmacological agents used in this study. Because the frequency characteristics represent the working of only the dynamic phase of a sustained indentation response, this once again suggests that the static and dynamic portions of the response represent very different mechanisms at work.
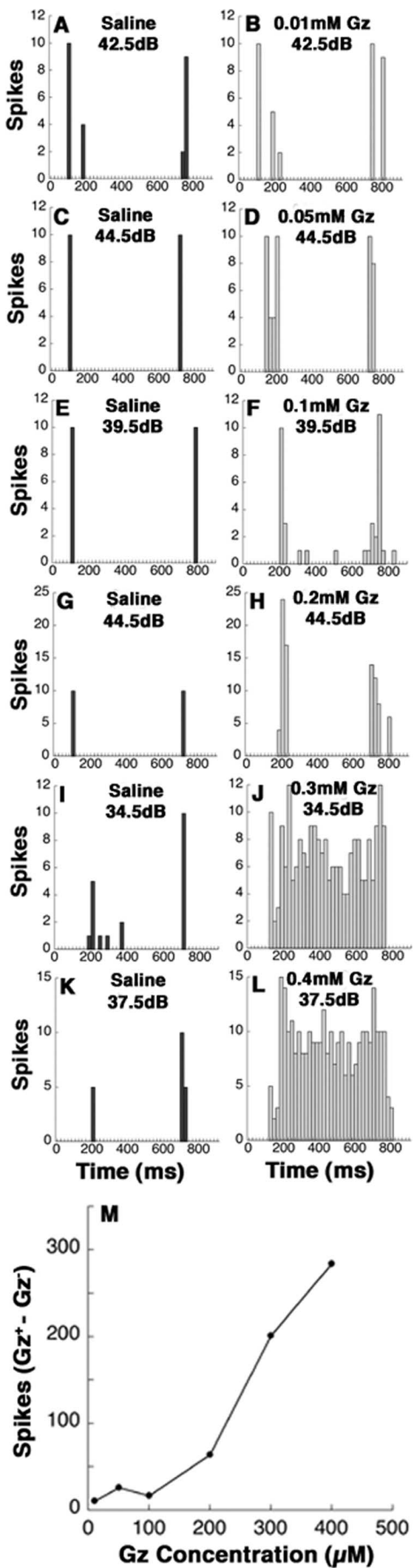

Figure 9. PST histograms for six different $P C S$, depicting the response to ramp-and-hold stimuli, before and after the addition of gabazine (Gz) (from 10 to $400 \mu \mathrm{m}$ ). $A, C, E, G, I$, PST histograms just before addition of gabazine for each concentration. $\boldsymbol{B}$, Gabazine at $10 \mu \mathrm{m}$ added to the bathing solution; $\boldsymbol{D}, 50 \mu \mathrm{m}$ gabazine; $\boldsymbol{F}, 100 \mu \mathrm{m}$ gabazine; $\boldsymbol{H}, 200 \mu \mathrm{m}$ gabazine; $\boldsymbol{J}, 300$ $\mu \mathrm{m}$ gabazine; $\boldsymbol{L}, 400 \mu \mathrm{m}$ gabazine; $\boldsymbol{M}$, dose-response curve for gabazine. The ordinate depicts the additional spikes present during ramp-and-hold stimuli with the addition of gabazine to the bathing solution of the $P($ at each concentration (e.g., number of spikes in $\boldsymbol{B}$ minus those in $\boldsymbol{A}$ ). Gabazine concentration is depicted on the abscissa. 


\section{Discussion}

Our results present a novel picture of the RA response of the Pacinian corpuscle, which suggests the model for a mechanochemical rapid adaptation process in the PC in Figure 12. In this model, the mechanical properties of the PC capsule produce a much higher probability of action-potential generation during the dynamic portion of the ramp-and-hold stimulus (i.e., start and end of on-and-off ramps) than during the static portion (hold). After the initial opening of mechanogated channels at the onset of a mechanical stimulus, the depolarization caused by the receptor potential induces the release of glutamate from clear-core vesicles of the neurite (Fig. 12, three green arrows denoting pathway at top). This glutamate acts either on the lamellar cells or both the lamellar cells and the neurite. On the neurite, glutamate acts as an excitatory neuromodulator to cause firing, which is seen as the static spikes (perhaps also increasing the probability of dynamic spikes). On the lamellar cells, glutamate induces GABA release (Fig. 12 , red arrow), which inhibits the static responses (and perhaps some of the dynamic). The neurotransmitter release may be induced another way: the mechanical stimulus alone may be responsible for the release of either the glutamate (green arrow pointing downward) or the GABA (or both) from the modified Schwann cells of the capsule. Thus, for the PC, the low probability of spike generation during the static phase of sustained indentation cannot be entirely attributable to the mechanical properties of the capsule, because it is significantly increased in the presence of gabazine and picrotoxin and decreased in the presence of GABA and kynurenate.

This model stems from our results as well as those of other investigators. For example, the positive labeling of both synaptobrevin (Fig. $2 A, B$ ) and GABA receptors (Fig. 2C,D) implies synaptic-like interaction between the neurite and the inner-core cells. Also, there are synaptic-like thickenings on membranes $(\mathrm{Mt})$ of both sides of the close connections between the lamellar cells and the neurite (Fig. 1C,D), which have been called desmosomes by some investigators (Santini, 1976; Zelená, 1978). Santini (1976) proposed this Mt, or "receptripse," as the site of mechanotransduction. Although neither of these possibilities has yet been ruled out, the presence of clear-core vesicles in the lamellar cells (Malinovsky et al., 1990) (Fig. 1C,D, red arrowheads) and in the neurite (Fig. $1 C, D$, black arrows) in close proximity to these thickenings suggest a synaptic-like connection at this site. These Mts are similar to those seen in the Merkel cell-neurite complexes, and, although Gottschaldt and Vahle-Hint (1981) referred to them as desmosomes, many others liken them to synaptic-like structures or contacts (Chen et al., 1973; Halata 1975; Halata et al., 2003; Shimohira-Yamasaki et al., 2006). Until recent findings concerning glial-neuronal bidirectional communication (Cornell-Bell et al., 1990; Nedergaard, 1994; Parpura et al., 1994; Araque et al., 2000, 2001; Innocenti et al., 2000), this chemical interaction between the neurite and inner-core cells was not considered possible (Davis, 1961). This was the case specifically because the first classical synapse for the PC is thought to be in the spinal cord or medulla (Brown et al., 1980).

The pharmacological experimental results are depicted in the PST histograms of Figures 4-7 and 9. The PSTs histograms demonstrate that, in saline alone, the PC shows an RA response to ramp-and-hold stimuli. With the addition of GABA antagonists such as gabazine or picrotoxin, many static spikes occur, and they

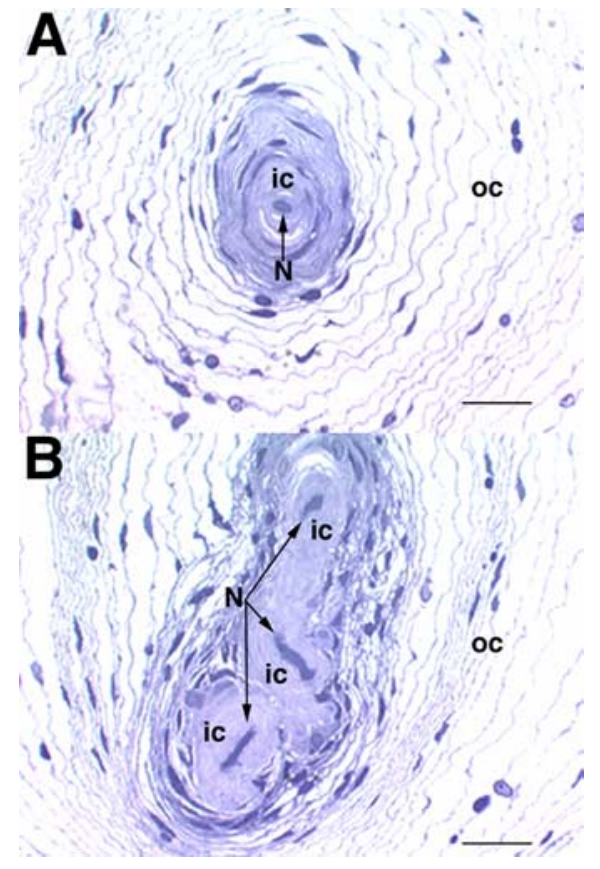

Figure 10. Light micrographs of $1 \mu \mathrm{m}$ cross-sections through the terminal portion of the $P C$ from Figure 5i. $\boldsymbol{A}$, Neurite (N) inner-core hemi-lamellae (ic) and outer core (oc) lamellae. $\boldsymbol{B}$, Section approximately $300 \mu \mathrm{m}$ from the ultra-terminus in which three distinct neurites (N) are seen, inner-core (ic) hemi-lamellae, and the outer-core (oc) cells surround all three groups (neurite + ic.) Scale bars, $25 \mu \mathrm{m}$.

are totally eliminated with the addition of GABA. With the addition of GABA antagonists, the response becomes much more slowly adapting, similar to that of the MCN (Fagan and Cahusac, 2001). To better compare our results to the MCN data, a 4 s hold time was used in one picrotoxin experiment (Fig. 6). Because the electrophysiological results were obtained from isolated PCs, GABA cannot be from an efferent source as suggested by Panek et al. (2002) in the spider tactile organ.

After finding the GABAergic inhibition, it was proposed that glutamate excitation occurring after the mechanical onset depolarization is responsible for the static spikes, because glutamate has been implicated as at least partially responsible for the static portion of the response of the MCN (Fagan and Cahusac, 2001). Findings from another somatosensory mechanoreceptor (proprioceptor), the muscle spindle, show that clear-core vesicles in the nerve endings contain glutamate and release this transmitter during stimulation, suggesting an autogenic excitatory (modulatory) effect on the muscle spindle (Bewick et al., 2005). Similar clear-core vesicles are seen in PC neurites (Figs. 1C,D; 11, black arrows) and glutamate receptors (mGluR1a) have been found on the membranes of both the neurite and the inner-core lamellar cells (Pawson et al., 2007). Thus, findings in the PC, together with those of other receptors (Fagan and Cahusac, 2001; Bewick et al., 2005), are consistent with the possibility that glutamate-mediated excitation in the PC is responsible for the SA-like spikes of the static portion of ramp-and-hold stimuli, which is inhibited in the presence of GABA and revealed in the presence of picrotoxin or gabazine in a manner that is both dose dependent (gabazine) (Fig. 9) and statistically significant (Fig. 8). The release of glutamate from vesicles of the depolarized neurite may be the stimulus needed for the lamellar cells to discharge the inhibitory neurotransmitter (for review, see Carmignoto 2000; Araque et al., 2001). However, mechanical stimulation 


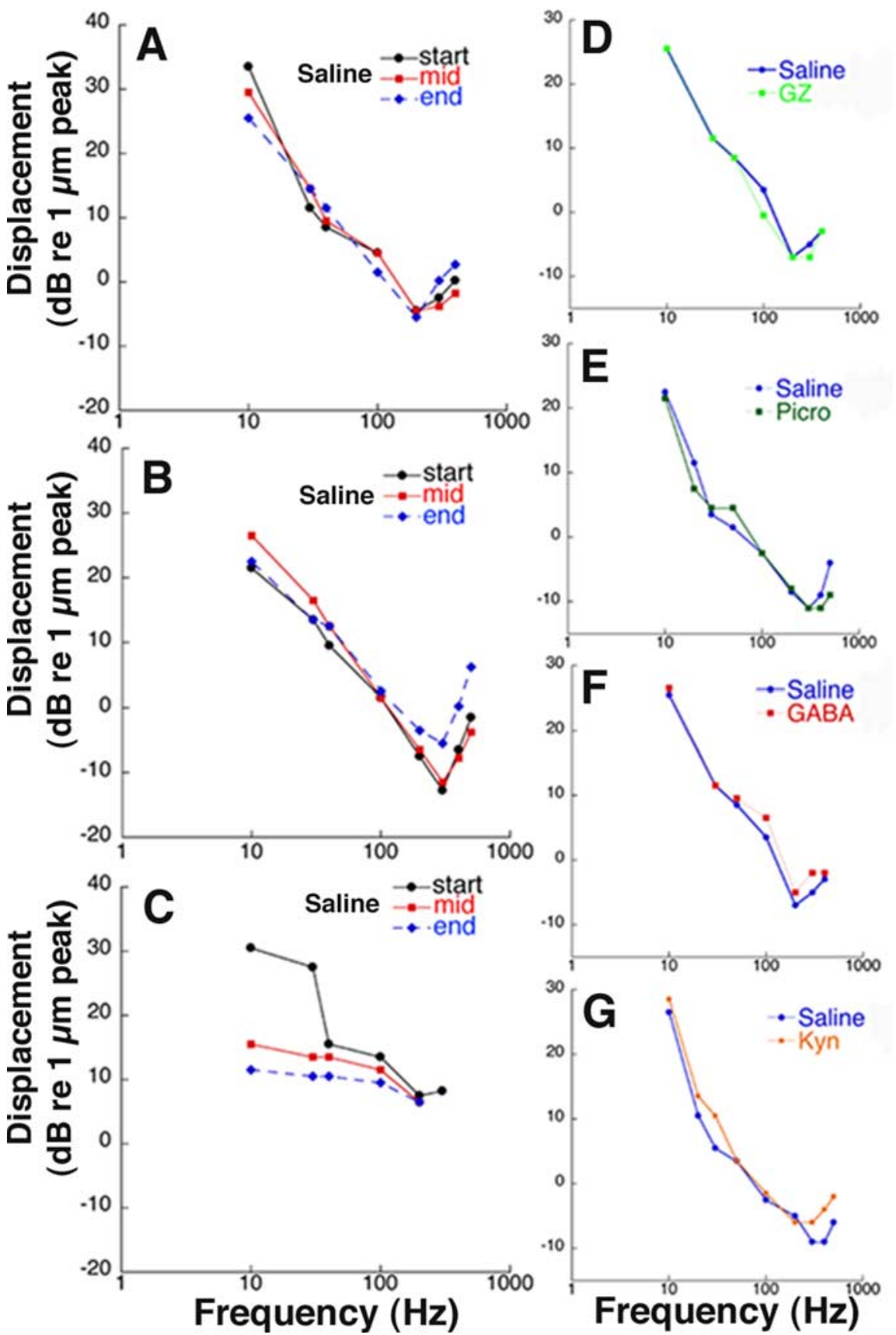

Figure 11. Frequency characteristics $(\mathrm{FC})$ recorded during experiments, over a range of $10-400 \mathrm{~Hz}$ using a criterion of $\sim 1$ spike/s. $A, P C$ from experiment of Figure 4ii. The FC did not appear to change over the course of the experiment. The bf for this $\mathrm{PC}$ was $200 \mathrm{~Hz}$. B, PC from Figure 4i. The bf was $300 \mathrm{~Hz}$. The only curve that appears to differ in this experiment is the one obtained at the close of the experiment in which the sensitivity decreased by $\sim 6 \mathrm{~dB}$. C, PC from Figure $5 i$. At the onset of the experiment, the FC was $U$ shaped, as expected, except that the PC responded in a much less sensitive manner and had a bf of $200 \mathrm{~Hz}$. As the experiment progressed, the bf remained constant, but the "curve" flattened out. D, FC taken, while the PC is bathed in saline only (blue) before addition of $0.3 \mathrm{~mm}$ gabazine $(\mathrm{Gz}$ ) and during the addition of $0.3 \mathrm{~mm}$ gabazine (light-green). $\boldsymbol{E}$, Saline (blue) before picrotoxin (Picro) and during $4 \mathrm{~mm}$ picrotoxin (dark-green). $\boldsymbol{F}$, Saline (blue) before GABA and during $0.5 \mathrm{~m}$ GABA (red). $\boldsymbol{G}$, Saline (blue) before kynurenate (Kyn) and during $20 \mathrm{~mm}$ kynurenate (orange).

of the modified Schwann cells may be sufficient for GABA (Kozlov et al., 2006) or glutamate (Innocenti et al., 2000) to be released, either via vesicular release (Araque et al., 2000) or through connexin hemichannels (Ye et al., 2003).

The hypothesis that glutamate is responsible for the static spikes was tested by applying the ionic glutamate receptor channel antagonist kynurenate (10 or $20 \mathrm{~mm}$ ) to PCs that showed some "after onset" spiking in the presence of saline alone (Figs.
$5 A, E, 7 J$ ). In these cases, the static (and mid-ramp) spikes were greatly reduced, thus implicating glutamate excitation as the cause of the static spikes.

Thus, all of the above results led us to the aforementioned glial-neuronal mechanochemical model for rapid adaptation of the PC (first paragraph of Discussion and Fig. 12). We suggest that this model is part of an evolutionary process. The SA mechanoreceptors such as the MCN can be found in vertebrates such as salamanders, fish, and frogs (Scott et al., 1981; Whitear, 1989), as well as in mammals, whereas the rapidly adapting PCs are restricted to the higher vertebrates (Bell et al., 1994). Because glutamate is partially responsible for the static portion of the response of the MCN (Fagan and Cahusac, 2001), we suggest that the RA Pacinian corpuscle evolved by simply adding GABAergic inhibition during the static portion of a sustained indentation.

Rapid adaptation allows the PC to function as a highly sensitive detector of on and off stimuli such as sinusoids, thus giving higher vertebrates the advantage of picking up vibratory stimuli emanating from prey or predators. Also, although vibratory communication has been shown for a wide range of animals (Hill, 2001), the PC plays a major role in elephant communication. These animals emit lowfrequency sounds that travel through the ground and can be detected by PCs in the feet of other elephants up to five miles away (Bouley et al., 2007; O'ConnellRodwell, 2007).

In conclusion, it is noted that, since the 1950s, investigators have been examining the mechanical properties of the capsule of the Pacinian corpuscle to solve the mystery of the RA response of this receptor to ramp-and-hold stimuli (Hubbard, 1958). By removing most of the lamellae from the PC, Lowenstein and his colleagues concluded that the capsule was responsible for the RA response because, without it, the PC responded as an SA receptor, and this led the investigators to attribute the rapid adaptation to the mechanical properties of the capsule (Loewenstein and Mendelson, 1965; Loewenstein and Skalak, 1966). Because none of the information concerning bidirectional interaction between neurons and glial cells was available at the time and given that the first neuronal-neuronal synapse for the PC takes place at the spinal cord or medulla (Brown et al., 1980), it was assumed that there could be no chemical excitation or inhibition possible at the far-reaching end of this mechanoreceptor. However, our results suggest that, directly after the mechanoreceptor onset response, GABA, emanating from the lamellar cells, inhibits 
glutamate excitation (either from the neurite or the lamellae). This leads to a mechanochemical, rather than solely mechanical, rapidly adapting response to sustained pressure. This type of neuromodulation, emanating from the modified Schwann cells of the inner core, indicates a glial-neuronal chemical interaction, which is a completely novel finding for this tactile mechanoreceptor.

\section{References}

Araque A, Li N, Doyle RT, Haydon PG (2000) SNARE protein-dependent glutamate release from astrocytes. J Neurosci 20:666-673.

Araque A, Carmignoto G, Haydon PG (2001) Dynamic signaling between astrocytes and neurons. Annu Rev Physiol 63:795-813.

Backoff PM, Palombi PS, Caspary DM (1997) Glycinergic and GABAergic inputs affect short-term suppression in the cochlear nucleus. Hear Res 110:155-163.

Backoff PM, Shadduck Palombi P, Caspary DM (1999) $\gamma$-Aminobutyric acidergic and glycinergic inputs shape coding of amplitude modulation in chinchilla cochlear nucleus. Hear Res 134:77-88.

Bell J, Bolanowski S, Holmes MH (1994) The structure and function of Pacinian corpuscles: a review. Prog Neurobiol 42:79-128.

Bewick GS, Reid B, Richardson C, Banks RW (2005) Autogenic modulation of mechanoreceptor excitability by glutamate release from synaptic-like vesicles: evidence from the rat muscle spindle primary sensory ending. J Physiol 562:381-394.

Bolanowski SJ Jr, Verrillo RT (1982) Temperature and criterion effects in a somatosensory subsystem: a neurophysiological and psychophysical study. J Neurophysiol 48:836-855.

Bolanowski SJ Jr, Zwislocki JJ (1984) Intensity and frequency characteristics of Pacinian corpuscles. I. Action potentials. J Neurophysiol 51:793-811.

Bouley DM, Alarcón CN, Hildebrandt T, O’Connell-Rodwell CE (2007) The distribution, density and three-dimensional histomorphology of Pacinian corpuscles in the foot of the Asian elephant (Elephas maximus) and their potential role in seismic communication. J Anat 211:428-435.

Brown AG, Fyffe RE, Noble R (1980) Projections from Pacinian corpuscles and rapidly adapting mechanoreceptors of glabrous skin to the cat's spinal cord. J Physiol 307:385-400.

Cahusac PM, Senok SS (2006) Metabotropic glutamate receptor antagonists selectively enhance responses of slowly adapting type I mechanoreceptors. Synapse 59:235-242.

Carmignoto G (2000) Reciprocal communication systems between astrocytes and neurons. Prog Neurobiol 62:561-581.

Caspary DM, Backoff PM, Finlayson PG, Palombi PS (1994) Inhibitory inputs modulate discharge rate within frequency receptive fields of anteroventral cochlear nucleus neurons. J Neurophysiol 72:2124-2133.

Chen SY, Gerson S, Meyer J (1973) The fusion of Merkel cell granules with a synapse-like structure. J Invest Dermatol 61:290-292.

Cornell-Bell AH, Finkbeiner SM, Cooper MS, Smith SJ (1990) Glutamate induces calcium waves in cultured astrocytes: long-range glial signaling. Science 247:470-473.

Davis H (1961) Some principles of sensory receptor action. Physiol Rev 41:319-416.

Fagan BM, Cahusac PMB (2001) Evidence for glutamate receptor mediated transmission at mechanoreceptors in the skin. Neuroreport 12:341-347.

Gai Y, Carney LH (2008) Influence of inhibitory inputs on rate and timing of responses in the anteroventral cochlear nucleus. J Neurophysiol 99:1077-1095.

Gottschaldt KM, Vahle-Hinz C (1981) Merkel cell receptors: structure and transducer function. Science 214:183-186.

Gray JA, Malcolm JL (1950) The initiation of nerve impulses by mesenteric Pacinian corpuscles. Proc R Soc Lond B Biol Sci 137:96-114.
Gray JA, Matthews PB (1951) Response of Pacinian corpuscles in the cat's toe. J Physiol 113:475-482.

Halata Z (1975) The mechanoreceptors of the mammalian skin ultrastructure and morphological classification. Adv Anat Embryol Cell Biol 50:3-77.

Halata Z, Grim M, Bauman KI (2003) Friedrich Sigmund Merkel and his "Merkel cell," morphology, development, and physiology: review and new results. Anat Rec A Discov Mol Cell Evol Biol 271:225-239.

Hill PSM (2001) Vibration and animal communication: a review. Am Zool 41:1135-1142.

Hubbard SJ (1958) A study of rapid mechanical events in a mechanoreceptor. J Physiol 141:198-218.

Innocenti B, Parpura V, Haydon PG (2000) Imaging extracellular waves of glutamate during calcium signaling in cultured astrocytes. J Neurosci 20:1800-1808.

Jha SK, Islam F, Mallick BN (2001) GABA exerts opposite influence on warm and cold sensitive neurons in medial preoptic area in rats. J Neurobiol 48:291-300.

Kozlov AS, Angulo MC, Audinat E, Charpak S (2006) Target cell-specific modulation of neuronal activity by astrocytes. Proc Natl Acad Sci U S A 103:10058-10063.

Loewenstein WR, Mendelson M (1965) Components of receptor adaptation in a Pacinian corpuscle. J Physiol 177:337-397.

Loewenstein WR, Skalak R (1966) Mechanical transmission in a Pacinian corpuscle. An analysis and a theory. J Physiol 182:346-378.

Malinovsky L, Pac L, Vega-Alvarez JA, Bozilow W (1990) The capsule structure of Pacinian corpuscles from the cat mesentery. Z Mikrosk Anat Forsch 104:193-201.

Nedergaard M (1994) Direct signaling from astrocytes to neurons in cultures of mammalian brain cells. Science 263:1768-1771.

O'Connell-Rodwell CE (2007) Keeping an "ear" to the ground: seismic communication in elephants. Physiology (Bethesda) 22:287-294.

Pacini F (1838) Sopra un particolare genere di piccoli Corpi Globulari scoperti nel umano. Proc Florentine Med Phys Soc (Reprinted 1924) Sperimentale 78:275.

Panek I, French AS, Seyfarth EA, Sekizawa S, Torkkeli PH (2002) Peripheral GABAergic inhibition of spider mechanosensory afferents. Eur J Neurosci 16:96-104.

Parpura V, Basarsky TA, Liu F, Jeftinija K, Jeftinija S, Haydon PG (1994) Glutamate-mediated astrocyte-neuron signaling. Nature 369:744-747.

Pawson L, Bolanowski SJ (2002) Voltage-gated sodium channels are present on both the neural and capsular structures of Pacinian corpuscles. Somatosens Mot Res 19:231-237.

Pawson L, Slepecky NB, Bolanowski SJ (2000) Immunocytochemical identification of proteins within the Pacinian corpuscle. Somatosens Mot Res 17:159-170.

Pawson L, Pack AK, Bolanowski SJ (2007) Possible glutaminergic interac- 
tion between the capsule and neurite of Pacinian corpuscles. Somatosens Mot Res 24:85-95.

Pease DC, Quilliam TA（1957） Electron microscopy of the Pacinian corpuscle. J Biophys Biochem Cytol 3:331-342.

Rottman JB, Freeman EB, Tonkonogy S, Tompkins MB (1995) A reverse transcription-polymerase chain reaction technique to detect feline cytokine genes. Vet Immunol Immunopathol 45:1-18.

Santini M (1976) The "receptripse": the desmosome-like lamellar-axonal junction subserving mechano-electric transduction and effecting the sympathetic actions on the Pacinian sensor. In: Sensory functions of the skin of primates, with special reference to man (Zotterman Y, ed), pp 37-42. Oxford: Pergamon.

Sato M (1961) Response of Pacinian corpuscles to sinusoidal vibration. J Physiol 159:391-409.

Scott SA, Cooper E, Diamond J (1981) Merkel cells as targets of the mechanosensory nerves in salamander skin. Proc R Soc Lond B Biol Sci 211:455-470.
Shimohira-Yamasaki M, Toda S, Narisawa Y, Sugihara H (2006) Merkel cell-nerve cell interaction undergoes formation of a synapse-like structure in a primary culture. Cell Struct Funct 31:39-45.

Spencer PS, Schaumburg HH (1973) An ultrastructural study of the inner core of the Pacinian corpuscle. J Neurocytol 2:217-235.

Whitear M (1989) Merkel cells in lower vertebrates. Arch Histol Cytol 52:415-422.

Ye ZC, Wyeth MS, Baltan-Tekkok S, Ransom BR (2003) Functional hemichannels in astrocytes: a novel mechanism of glutamate release. J Neurosci 23:3588-3596.

Zelená J (1978) The development of Pacinian corpuscles. J Neurocytol 7:71-91.

Zelená J (1994) Pacinain corpuscles. In: Nerves and mechanoreceptors: the role of innervation in the development and maintenance of mammalian mechanoreceptors, pp 138-185. New York: Chapman and Hall. 